\title{
Relationship between Sustainable Development of Branches of Fuel and Energy Complex and Growth GDP
}

\author{
M. A. Makhkamova, G. J. Allaeva
}

\begin{abstract}
The article discusses the relationship between the development of fuel and energy Uzbekistan with GDP growth (gross domestic product). Data are provided on the forecast growth rates of the world economy, the average developed countries and Uzbekistan, factors for ensuring GDP growth in tandem with the efficiency of the use of fuel and energy resources. Based on the cross-country regression analysis, the model of the influence of the energy system performance index (EAPI) on GDP growth is shown.
\end{abstract}

Key words: fuel and energy complex, sustainable economic development, energy balance, energy structure, energy intensity of GDP, cross-country regression analysis, innovative energy, energy resources, investments, unit investment, energy cost..

\section{INTRODUCTION}

An important result of the economic reforms implemented in Uzbekistan was the technical and technological renewal of one of the key sectors of the real sector - the fuel and energy complex (FEC). As early as 1995, Uzbekistan achieved oil and, in general, energy independence. At present, given the republic's self-sufficiency, measures are being taken for the medium and long-term satisfaction of its needs with the necessary quality energy resources on the basis of sustainable innovative development of the industry.

In the Action Strategy for the five priority areas of the country's development in 2017-2021, the country's leadership identified the main objectives for reducing the energy intensity of the economy, ensuring the rational and efficient use of non-reproducible hydrocarbon resources in Uzbekistan, as well as "ensuring balance and sustainability of the national economy, increasing its share industry, .... reduction of energy intensity and resource intensity of the economy, widespread introduction of energy-saving technologies into production, expansion ix renewable energy, increase in labor productivity in the economy; ... to ensure sustainable high rates of growth of gross domestic product by maintaining macroeconomic balance, deepening of structural and institutional reforms on the basis of implementation of the adopted medium-term programs. "

The fuel and energy sector plays a key role in the development of the economy of Uzbekistan: almost 50\% of capital investments go to this sector, it accounts for $22.7 \%$ of the total gross domestic product (GDP). Concrete measures are being taken to increase the efficiency of using power plants, reduce

Revised Version Manuscript Received on 16 September, 2019.

* Correspondence Author

Dc.S Prof. M.A.Makhkamova, Tashkent State Technical University, Tashkent, Uzbekistan

Ph.D. G. J. Allaeva, Tashkent State Technical University, Tashkent, Uzbekistan, allaeva74@mail.ru specific energy consumption, reduce the share of natural gas by increasing the use of coal in the energy production process, based on modernization, technical and technological re-equipment of enterprises, introducing resource-saving technologies, and, as a result, ensuring reliable and quality supply consumers with electrical and thermal energy in the long term [1].

However, the economy of Uzbekistan is very energy intensive by international standards. Uzbekistan is inferior in this respect to the average for the countries of Western Europe - by 4-5 times, the USA - by 3.5 times, Japan and Korea - more than 4 times. In the group of CIS countries, Uzbekistan has the highest value for this indicator. The energy intensity of Uzbekistan's GDP exceeds the current value of this indicator in Russia by $80 \%$, Kazakhstan by $70 \%$, and Ukraine by $20 \%$ (Fig. 1) [9].

This is due to the use of technologically outdated equipment, a high proportion of fuel and energy resources in the country's exports, relatively low prices for electricity and some types of fuel, inadequate accounting for the production and consumption of electricity and energy resources, etc.

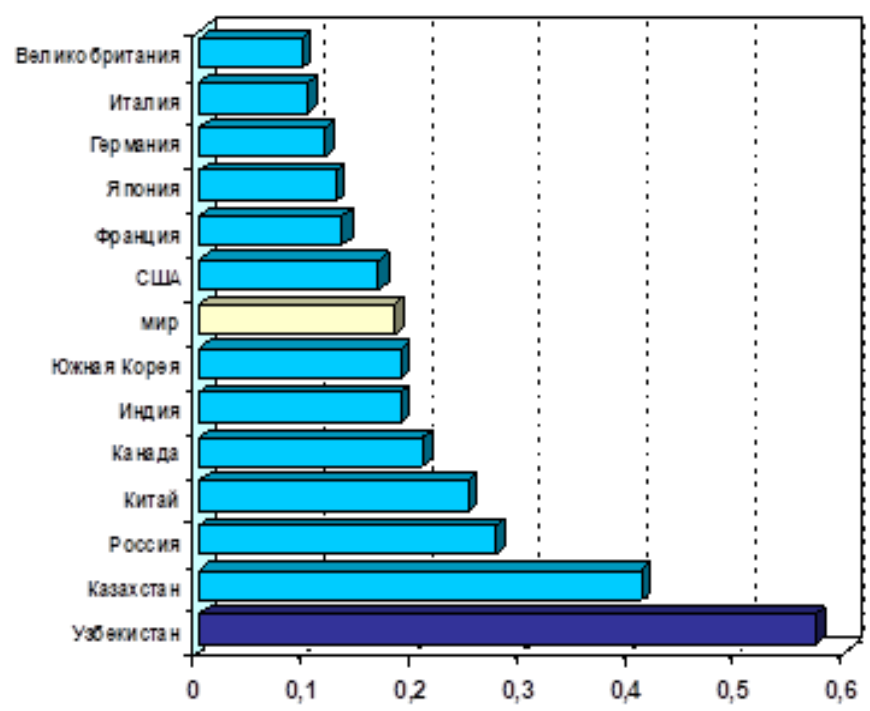

Fig. 1. The energy intensity of GDP at PPP of Uzbekistan in comparison with other countries (t.e. / thousand dollars.) [8]

On the other hand, the global economic crisis has demonstrated the scientific and practical importance of preventing the future sharp fall in the world's GDP by realizing the economic and innovative potential of their fuel and energy complexes. Being the backbone structure of the global economy, they are able to generate and maintain

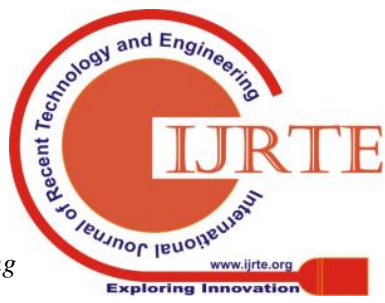


economic growth, ensure an increase in the well-being of the population, reduce poverty, level climate cataclysms without additional investment: by increasing the innovative potential of national and world economic systems.

Medium-term targets for the development of the national economy are determined by the need to address the long-term goal of maximizing the gap in the development of the economy of Uzbekistan with the average level of development of developing countries. An assessment of the development prospects of countries belonging to the category of middle-developed countries of the world was made in conjunction with the development of the world economy as a whole. Forecast estimates showed that the growth of the world economy for the period 2018-2025gg. will be $-3.8-4.1 \%$ in average annual terms, with a subsequent reduction to $3.5 \%$ by the end of the forecast period. The growth rate of countries belonging to the category of moderately developed countries of the world will be about $4 \%$ (Fig. 2).

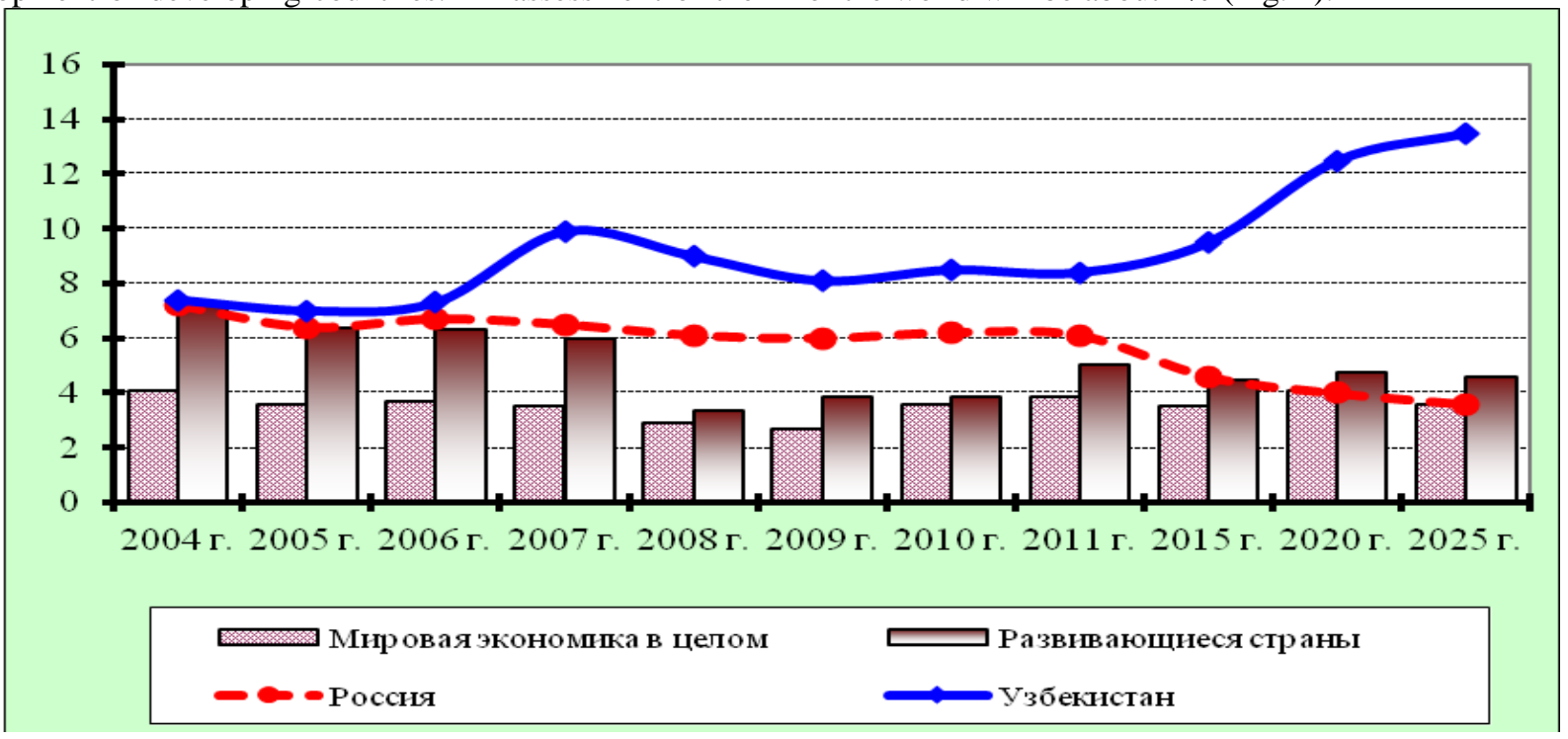

Fig. 2. Forecast growth rates of the world economy, medium-developed countries and Uzbekistan (as a percentage of the previous year)

We conducted a study of the relationship between the development of the fuel and energy complex and the growth of gross domestic product (hereinafter GDP) using mathematical modeling and cross-country regression analysis (based on WEF data for 2007-2016). This study showed that the positive growth of the so-called EAPI (Energy Architecture Performance Index) is important for sustainable GDP growth, and in general, for the country's economy.

The analysis allowed us to formalize the so-called scatter diagram (Fig. 3) (from the English. Scatter - spread), which confirms our conclusion that the energy-efficient infrastructure of the energy complex closely interacts with the development of the national economy and plays a leading role in the growth of the national economy. GDP.

The EAPI index, in turn, consists of three sub-indices: economic growth and development (economic growth and development (EGD), environmental sustainability (ENSUS), and energy access and security (ENAS), which are calculated on basis of nine indicators (Table 1).

Based on empirical models for assessing the impact of international indices and their components, the model of the influence of the energy system performance index (EAPI) and its sub-indices on GDP growth has the following log-linear form:

$$
\begin{aligned}
& \log \left(G D P_{i}\right)=\beta_{0}+\beta_{1} E G D_{i}+\beta_{\mathbf{2}} E N S U S_{i}+\beta_{\mathbf{3}} E N A C_{i}+\beta_{\mathbf{4}} P O P_{i}+\beta_{\mathbf{5}} S U R F_{i \mathrm{I}}+u_{i}, \\
& i=1, \ldots, 108
\end{aligned}
$$

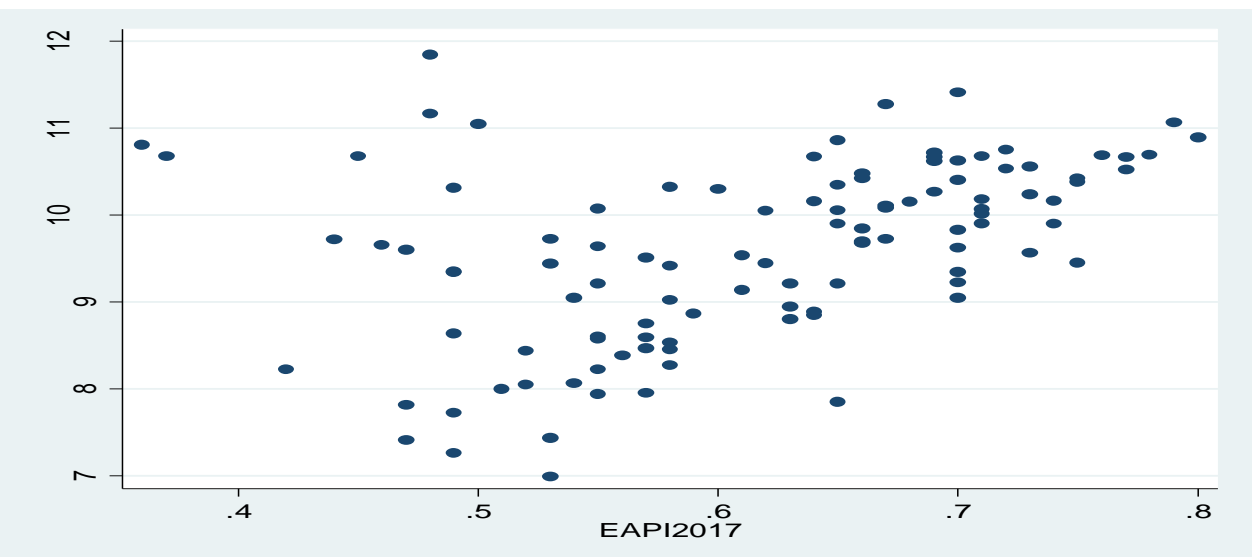

Figure 3. Scatter diagram of GDP per capita and EAPI (energy architecture performance index) for 2017 
The dependent variable $\log \left(G D P_{i}\right)$ - is the logarithm of GDP per capita - the average for 2009-2016, the independent variables $E G D_{i}-$ is the sub-index of economic growth and development, ENSUS $S_{i}$ is the sub-index of environmental sustainability, $E N A C_{i}$ is the sub-index of energy access and security for 2016 ., LPOP $_{i}$ is the logarithm of the population of the country $i$ - is the average value for 2009-2016, LSURF is the logarithm of the size of the territory of the country, $u_{i}$ is the standard error of regressions. The variables LPOPi и LSURFi are control variables to increase the statistical stability of the results.

Table 1. Energy System Performance Index (EAPI) ${ }^{2}$

\begin{tabular}{|c|c|c|}
\hline Energy System Object & Index & Calculated based on \\
\hline \multirow{3}{*}{ 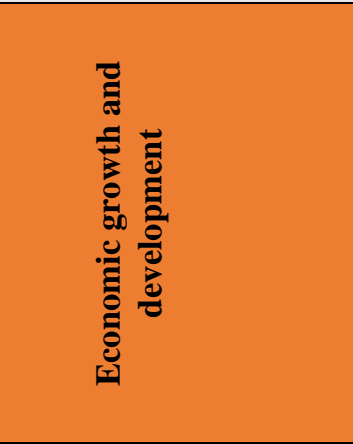 } & Energy intensity & Energy use per unit of GDP \\
\hline & Support / growth barriers & Energy import cost (\% of GDP) \\
\hline & Availability & $\begin{array}{l}\text { The degree of artificial distortion of the } \\
\text { price of gasoline (index) } \\
\text { The degree of artificial distortion of diesel } \\
\text { prices (index) } \\
\text { Electricity prices (US \$ per } \mathrm{kW} \text { ) }\end{array}$ \\
\hline \multirow{2}{*}{ 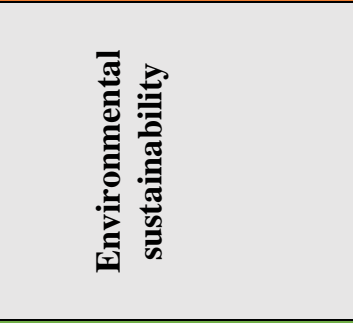 } & $\begin{array}{l}\text { The ratio of fuel sources with low } \\
\text { carbon content in the energy mix }\end{array}$ & $\begin{array}{l}\text { alternative and atomic energy (\% of total } \\
\text { energy use, including biomass) }\end{array}$ \\
\hline & Impact of emissions & $\begin{array}{l}\text { Hydrocarbon emissions from energy } \\
\text { production. }\end{array}$ \\
\hline \multirow{3}{*}{ 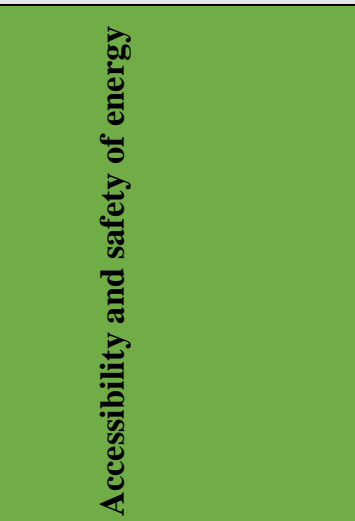 } & Level and quality of access & Methane emissions in the energy sector. \\
\hline & Diversified power supply & Nitrate emissions in the energy sector. \\
\hline & Self sufficiency & Average fuel consumption for cars. \\
\hline
\end{tabular}

An analysis of the regression results showed that the impact of all sub-indices of the energy system performance (EAPI) is statistically significant, and also has the correct signs. However, the LSURFi results showed that the country's area does not affect GDP, which is consistent with the findings of other researchers. The sub-index of economic growth and development affects the growth of GDP, that is, an increase in this sub-index by one standard deviation $(0.12$ p.) Increases GDP by $6.1 \%$. The environmental sustainability sub-index adversely affects GDP. This can be explained by the fact that this indicator is calculated on the basis of emissions into the environment and the use of alternative energy, which is the most expensive today. Consequently, environmental protection is very important, but at the same time reducing the current economic growth factor in order to ensure the sustainability of human development. The sub-index of accessibility and security of energy has the highest value in economic development. The subindex growth by one standard deviation (0.17) increases GDP by $45 \%$. Since this subindex covers the level and quality of power supply, it shows the high importance of the energy infrastructure. The population indicator also has a high statistical significance. Hence, in this case, the growth of the country's population will have a negative impact on the per capita GDP. This is explained by the fact that the rate of improvement of the energy infrastructure is lower than the natural increase in the population of the countries in question.

Thus, the conducted inter-country regression analysis confirmed the undoubted direct correlation between the effective development of the fuel and energy complex, GDP and the steady growth of the national economy as a whole. Consequently, the main task for the period up to 2020-2030. is to ensure macroeconomic stability and sustainable high rates of economic growth, improvement of its quality

\footnotetext{
${ }^{2}$ Источник: таблица составлена автором на основе данных ВЭФ за 2014-2017 гг.
} 
parameters due to further diversification of economic sectors. Especially this direction is relevant for the energy industry, given its system-forming role in the economy of Uzbekistan.

Ensuring the predicted production volumes of primary fuel and energy resources according to the favorable scenario for the development of the raw material base of the fuel and energy complex will allow to maintain the achieved level of prospective demand at an acceptable level, but with an unconditional decrease in the energy intensity of GDP from

Table 2.

Factors ensuring the growth of GDP and the required level of efficiency of use of fuel and energy resources ${ }^{3}$

\begin{tabular}{|c|c|c|c|c|c|c|}
\hline \multirow{2}{*}{$\begin{array}{c}\text { Name } \\
\text { indicators }\end{array}$} & $2013 \mathrm{y}$ & $2014 \mathrm{y}$ & $2015 \mathrm{y}$ & $2020 \mathrm{y}$ & $2025 \mathrm{y}$ & $2030 \mathrm{y}$ \\
\cline { 2 - 7 } & 87,90 & 89,83 & 92,025 & 96,715 & 98,325 & 105,0 \\
\hline $\begin{array}{c}\text { Expected demand for } \\
\text { primary TER, thous. }\end{array}$ & 0.52 & 0.49 & 0.46 & 0.35 & 0.30 & 0.28 \\
\hline $\begin{array}{c}\text { Energy intensity of GDP, } \\
\text { kg.N.e / thous. }\end{array}$ & &
\end{tabular}

\section{CONCLUSION}

Consequently, to achieve this level of development, Uzbekistan will need significantly higher GDP growth rates from $8.6-9.5 \%$ in $2012-2016$. to $12.5-13.5 \%$ in $2020-2025$, with their subsequent moderate reduction, but not less than 11.5-12.0\% [8]. The main conditions for achieving such high rates of economic growth should be: the growth of export potential, improving the structure of the economy, as well as the sustainable development of the republic's energy sector, through more efficient use of fuel and energy resources, the introduction of innovative energy production and processing technologies, and the growth of the energy efficiency index complex (EAPI).

\section{REFERENCES}

1. Decree of the President of the Republic of Uzbekistan No. UP-4947 dated February 7, 2017 "On the strategy of actions for the further development of the Republic of Uzbekistan".

2. National report on the Republic of Uzbekistan. Compiled as part of the United Nations Economic Commission for Europe project "Improving the synergy effect of the national programs of the CIS member countries on energy efficiency and energy saving to increase their energy security." Author: Jamshid Abdusalamov Uzbekenergo 2013.

3. Uvraimov I.A. Overview of key trends in the global and Central Asian oil and gas market. Uzbek Journal of Oil and Gas. Special release, May, 2013, p.28-35.

4. Allaev K.R. Energy of the world and Uzbekistan. Molia, 2007,388 p.

5. Alternative energy sources: use in Uzbekistan. Analytical report. Center for Economic Research. UNDP 2011, 74 p.

6. Energy saving and energy management: studies. manual / A.A. Andrizhievsky, V.I. Volodin. - Mn.: Your. school., 2005.- 294 p.

7. Energy policy in Uzbekistan: prospects for the development of the energy sector and benchmarks for diversifying the balance of primary energy sources as part of the transition to a resource-saving development model.

8. Bikeeva E. Analytical report. IAMI 2015

9. Energy saving as a factor of increasing efficiency in the implementation of innovative technologies in energy companies. Allaeva G.ZH. Problems of energy and resource conservation. Magazine number 4, 2014 212-215 p.

10. World Energy Report 2015: Growth Through Shocks / ed. Crotty R., Misrahi T.: World Economic Forum. 2017
$0.60 \mathrm{~kg} . \mathrm{e} / \mathrm{thousand}$ to $0.46-0.30 \mathrm{~kg}$. ne / thou. dollars in $2018-2020 \mathrm{gg}$. and up to $0.35-0.30 \mathrm{~kg}$.e / thousand dollars in 2025-2030. (tab. 2). The level of self-sufficiency, taking into account the preservation of export volumes of fuel and energy resources will be in the period 2020-2030. - 0.96 - 0.94 (i.e., the total demand for primary fuel and energy resources will be only $4-6 \%$ covered by imports of oil and condensate versus $1-2 \%$ in 2010-2015). [8] 